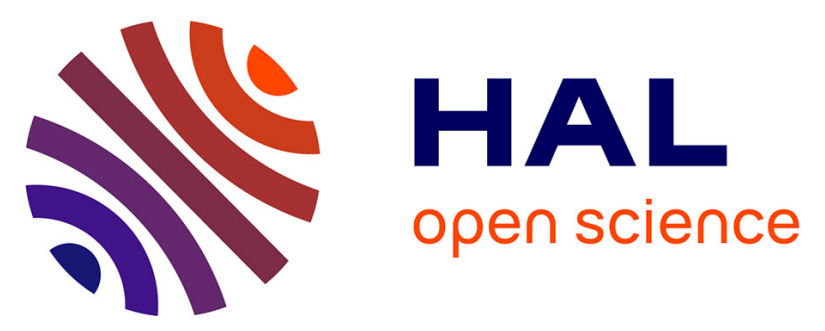

\title{
The decoupling of farm programs: revisiting the wealth effect
}

\author{
Fabienne Femenia, Alexandre Gohin, Alain Carpentier
}

\section{To cite this version:}

Fabienne Femenia, Alexandre Gohin, Alain Carpentier. The decoupling of farm programs: revisiting the wealth effect. 108. EAAE seminar: Income stabilization in a changing agricultural world: policy and tools, European Association of Agricultural Economists (EAAE). INT., Feb 2008, Varsovie, Poland. 18 p. hal-01462441

\section{HAL Id: hal-01462441 \\ https://hal.science/hal-01462441}

Submitted on 3 Jun 2020

HAL is a multi-disciplinary open access archive for the deposit and dissemination of scientific research documents, whether they are published or not. The documents may come from teaching and research institutions in France or abroad, or from public or private research centers.
L'archive ouverte pluridisciplinaire HAL, est destinée au dépôt et à la diffusion de documents scientifiques de niveau recherche, publiés ou non, émanant des établissements d'enseignement et de recherche français ou étrangers, des laboratoires publics ou privés.

\section{(ㅇ)(1) $\$$}

Distributed under a Creative Commons Attribution - NonCommercial - NoDerivatives| 4.0 
The decoupling of farm programs: Revisiting the wealth effect

Fabienne Féménia, Alexandre Gohin and Alain Carpentier

INRA ESR UR122 Rennes

4, allée Adolphe Bobierre

CS 61103

35011 Rennes cedex

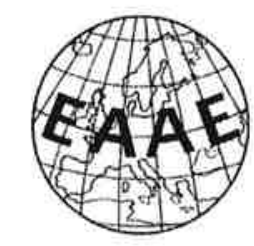

Paper prepared for presentation at the $108^{\text {st }}$ EAAE Seminar 'Income stabilisation in a changing agricultural world: policy and tools', Warsaw, Poland, 8-9 February, 2008.

Copyright 2008 by Fabienne Féménia, Alexandre Gohin and Alain Carpentier. All rights reserved. Readers may make verbatim copies of this document for noncommercial purposes by any means, provided that this copyright notice appears on all such copies. 


\title{
The decoupling of farm programs: Revisiting the wealth effect
}

\author{
Fabienne Féménia, Alexandre Gohin and Alain Carpentier \\ INRA ESR UR122 Rennes \\ 4, allée Adolphe Bobierre \\ CS 61103 \\ 35011 Rennes cedex
}

\begin{abstract}
:
Recent reforms of agricultural policies in developed countries introduced direct payments to the detriment of traditional production enhancing instruments. Whereas these new instruments can influence production through several effects, current empirical studies do not show any significant impact on production; direct payments mainly increase land values. In this article, we revisit the evaluation of the coupling effects passing through the wealth of agricultural households. The initial wealth of these agents, while being mainly in form of land asset holding, is always assumed to be fixed. On the contrary we show theoretically and empirically that, once the impact of farm programs on initial wealth is properly accounted for, the measure of the coupling effects is considerably increased for direct payments and more much marginally for traditional policy instruments. We illustrate the impact of this initial wealth actualisation through a simulation of the suppression of the US corn policy. The impact of this policy was underestimated by two thirds.
\end{abstract}

Key words: agricultural policy, decoupling, wealth effect

\section{Introduction}

Agricultural policies of the European Union (EU) and the United States (US) have been considerably reformed over the last twenty years with the introduction of direct payments independent of production volumes to the detriment of traditional production enhancing instruments. The so-called decoupling process really started in 1985 in the US with the introduction of deficiency payments on arable crops based on historical yields. In the EU the McSharry's reform of 1992 also introduced direct subsidies independent of current yields to offset the drop of price support. This process is still operating in the recent Common Agricultural Policy (CAP) reforms and has been motivated by internal efficiency considerations (better economic efficiency in the agricultural income support) as well as by external pressures in the World Trade Organisation (WTO) format (less distortionary effects on exchanges).

These reforms of farm policies in developed countries have generated a huge economic literature trying to evaluate their effects. Many methodological frameworks have been developed to identify the proper effects of these direct payments on the productions, i.e. their coupling effects. In theory several micro-economic mechanisms establish a link between these direct payments and the farm production. They indeed modify i) the agricultural labour by modifying the labour/leisure arbitrage of farm household (Benjamin 1992); ii) the capital invested in agriculture by relaxing the potential constraints on credit market (Phimister 1995) ; iii) the number of farms by covering their fixed costs (Chau and de Gorter 2005); iv) the wealth of farmers and thus the incentive to produce for risk averse farmers (Hennessy 1998), v) the real wages and the employment level in different sectors through a general 
equilibrium effect linked to the public funding of these payments (Chambers 1995). Moreover, some eligibility criterions necessarily go with the definition of these direct payments (base area in the US, number of single farm payment and conditionality in Europe, land use restrictions in both countries). These definition criterions may as well create a link between payments and production (Bhaskar and Beghin 2007a for base area in the US, Courleux et al. 2007 for the number of European single farm payments). Finally, direct payments can theoretically modify the agricultural production through their technical efficiency provided that this efficiency depends on the input levels and also that one of the above mechanisms applies. For instance Serra et al. (2007) consider the case where direct payments have a wealth effect on risk averse producers leading them to increase their input use, which in turn has an impact on their technical efficiency.

From an empirical point of view, the current literature tends to show that the effects on production quantities of these direct payments are low. Their main effect is to increase the value of land for purchase/sale or rent (Bhaskar and Beghin 2007b). However this interim synthesis is based upon sometimes quite a limited number of empirical studies. The most consequent literature concerns the measurement of the effects of direct payments through the wealth effect of risk averse farmers.

${ }^{1}$ All these studies consensually show that direct payments have a low effect on productions simply because they have small impact on the wealth of farmers. In that case, the degree of risk aversion of these farmers (and the wealth elasticity of production) does not matter a lot.

The main idea advanced in this article is that all these studies underestimate the effect of direct payments on the wealth of farmers who own the factors (land) on which these payments are defined. ${ }^{2}$ In fact the observed wealth of a farm household depends, among others, on the benefits that are expected from farming. The future direct payments are part of these expected benefits. So it must be taken into account that the wealth of a farm household, observed at a given time, depends among others on the expectations of different actors concerning the durability of direct payments. This implies that the initial wealth should not be considered as fixed as this is currently done in econometric analysis or in simulation models. In other words, our idea is that one must also modify the initial wealth of a risk averse farm household when identifying the decoupling of farm programs in general and of direct payments in particular. This new effect obviously depends on the structure of farm households' wealth. In particular this effect is null if the farm household does not own farmland at all, which is the usual factor capturing the direct payments in the long run. In such case, benefits of farm programs are completely passed to the landowners. On the contrary, if the farm household partly owns farmland, then he will capture part of the benefits of farm programs. In that case, this farm household will be better off, will become less risk averse if his risk aversion is decreasing with wealth and finally will produce more.

By explaining the initial wealth of a farm household, we simultaneously pay attention to the final beneficiary of direct payments. Available analyses with risk averse producers generally focus on the production impacts of direct payments without measuring their impacts on land values and farm household welfare. In these analyses, direct payments are represented as lump sump payments in the producer optimisation program and thus they do not translate into increased land values for instance. This is readily apparent in the analysis of Mullen et al. (2001) where the impacts on land values are reported. Their simulations show that the US landowner welfare increases much more with the coupled loan deficiency payments than with the more costly US direct payments. On the contrary we clearly identify in this article the landowner rather than the farm producer as the final beneficiary of direct payments. Our analysis will thus comply with the well known fact that farm programs finally end up in increased land values (Bhaskar and Beghin 2007b). 
In this article we first theoretically demonstrate the impact that the explanation of farm household wealth has on the incidence of the farm programs on farm production and land values. We consider two farm programs: a traditional output subsidy which increases the average output price and a direct payment defined over historical yield and acreage. Then we develop a simulation model applied to a representative US corn farm to measure how this empirically modifies the impacts of these instruments.

The article is organised as follows. In a first section we derive the microeconomic behaviour of a risk averse farm household using a standard framework suitable for our objective (static, mono product, one source of risk only, perfect credit, land and labour markets). In this first section, we assume that the initial wealth of this farm household is fixed and he is able to keep the benefit of direct payments. In a second section we simultaneously explicit the formation of farm household's wealth and identify the ultimate beneficiary of direct payments. The production and land value impacts of both programs are still compared on an equal budgetary cost basis. In a third section we calibrate an empirical model applied to a representative US corn farm. In a fourth section we conduct illustrative simulations to underline the impacts of our modelling modifications. These first illustrative simulations are followed, in a fifth section, by a simulation of the effects of the US corn policy applied in 2001. Section six concludes by suggesting new directions of research for the analysis of the impacts of farm programs.

\section{The standard starting point with fixed initial wealth and lump sum direct payments}

\section{The assumptions}

We consider a simple framework of a farm household using his fixed human capital $(L)$ and two variable inputs: land $(T)$ and an aggregate including the other inputs $(I)$ to produce one good $(Y)$. The two variable inputs are combined in the production technology with a CES (Constant Elasticity of Substitution) function and decreasing returns to scale (due to fixed human capital). The farm household receives a direct payment $(D P)$ independent from his current activity. He faces just one source of risk: the price of his production $\left(P_{Y}\right)$ which expectation is $\mu_{P_{Y}}$ and standard deviation is $\sigma_{P_{Y}}$. We also assume that this farm household is risk averse and that his preferences are represented by a power utility function. Finally we assume in this section that his initial wealth $\left(W_{0}\right)$ is fixed.

All these assumptions pertain to the individual farm household and will define the optimal production and input demands given the market price of inputs and output. To this framework we add a land supply function, so that we will be able to identify the impacts on land rental rates. Like Mullen et al. (2001), we adopt a simple constant price elasticity form. In order to lighten the comparative statics, we assume that the price of other variable inputs is fixed. This assumption will be relaxed in the simulations sections.

\section{The optimal supply and demand functions}

Formally the farm household's program is thus written as follows: 
$\max _{Y, I, T} E U\left(W_{0}+\tilde{\pi}\right)=E\left(\frac{\left(W_{0}+\tilde{\pi}\right)^{1-\rho}}{1-\rho}\right)$

s.t. $\quad \tilde{\pi}=\widetilde{P}_{Y} . Y-P_{C I} . I-R . T+D P$

s.t. $Y=\alpha_{0} \cdot\left(\alpha_{1} \cdot I^{\sigma-1 / \sigma}+\left(1-\alpha_{1}\right) \cdot T^{\sigma-1 / \sigma}\right)^{\sigma \cdot \theta / \sigma-1}$

With $\tilde{\pi}$ the current profit, $\rho$ the risk aversion coefficient (assumed different from 1), $\alpha_{0}, \alpha_{I}, \sigma$ the CES function parameters and $\theta<1$ the returns to scale coefficient. Maximising the expected utility is equivalent to maximising the certainty equivalent of the final wealth defined as the expectation of the final wealth less the risk premium:

$\max E U\left(W_{0}+\tilde{\pi}\right) \Leftrightarrow \max \quad E C=E\left(W_{0}+\tilde{\pi}\right)-P R\left(W_{0}+\tilde{\pi}\right)$

Arrow and Pratt (1964) showed through Taylor developments that this risk premium could be approximated by:

$P R\left(W_{0}+\tilde{\pi}\right) \approx-\frac{1}{2} \cdot \frac{U^{\prime \prime}\left(W_{0}+E(\tilde{\pi})\right)}{U^{\prime}\left(W_{0}+E(\tilde{\pi})\right)} \cdot V A R\left(W_{0}+\tilde{\pi}\right)$

According to our assumptions on the sources of risk and the form of the utility function this risk premium can be approximated by:

$P R\left(W_{0}+\tilde{\pi}\right) \approx \frac{1}{2} \cdot \frac{\rho}{W_{0}+E(\tilde{\pi})} \cdot Y^{2} \cdot \sigma_{P_{Y}}{ }^{2}$

The farmer's program is finally written as:

$\max _{Y, I, T} \quad E C=W_{0}+\mu_{P_{Y}} . Y-P_{C I} . I-R . T+D P-\frac{1}{2} \cdot \frac{\rho}{W_{0}+E(\tilde{\pi})} \cdot Y^{2} \cdot \sigma_{P_{Y}}{ }^{2}$

s.t. $E(\tilde{\pi})=\mu_{P_{Y}} . Y-P_{C I} . I-R . T+D P$

s.t. $\quad Y=\alpha_{0} \cdot\left(\alpha_{1} \cdot I^{\sigma-1 / \sigma}+\left(1-\alpha_{1}\right) \cdot T^{\sigma-1 / \sigma}\right)^{\sigma \cdot \theta / \sigma-1}$

It is not possible to obtain an analytical solution neither for these optimal demands nor for the product supply. However it will be easier to analyse the effects of farm programs by decomposing this program in two steps. The first step consists in minimising the production costs for a given production quantity. The second step consists in maximising the certainty equivalent given the production costs. The first step is thus:

$\min _{Y, I, T} P_{C I} . I+R \cdot T$

$Y=\alpha_{0} \cdot\left(\alpha_{1} \cdot I^{\sigma-1 / \sigma}+\left(1-\alpha_{1}\right) \cdot T^{\sigma-1 / \sigma}\right)^{\sigma \cdot \theta / \sigma-1}$

Solutions of this first step are: 


$$
\begin{aligned}
& I=\left(Y / \alpha_{0}\right)^{1 / \theta} \cdot\left(\alpha_{1} / P_{C I}\right)^{\sigma} \cdot\left(\alpha_{1}^{\sigma} \cdot P_{C I}^{1-\sigma}+\left(1-\alpha_{1}\right)^{\sigma} \cdot R^{1-\sigma}\right)^{\sigma / 1-\sigma} \\
& T=\left(Y / \alpha_{0}\right)^{1 / \theta} \cdot\left(\left(1-\alpha_{1}\right) / R\right)^{\sigma} \cdot\left(\alpha_{1}^{\sigma} \cdot P_{C I}^{1-\sigma}+\left(1-\alpha_{1}\right)^{\sigma} \cdot R^{1-\sigma}\right)^{\sigma / 1-\sigma} \\
& C\left(P_{C I}, R, Y\right)=\left(Y / \alpha_{0}\right)^{1 / \theta} \cdot\left(\alpha_{1}^{\sigma} \cdot P_{C I}^{1-\sigma}+\left(1-\alpha_{1}\right)^{\sigma} \cdot R^{1-\sigma}\right)^{1 / 1-\sigma}
\end{aligned}
$$

Equations (7) mainly show that the ratio of variable inputs does not depend on the direct payment. The impact strictly passes through the production quantity effect. This quantity is solution of the second step program:

$$
\max _{Y} \quad E C=W_{0}+\mu_{P_{Y}} \cdot Y-C\left(P_{C I}, R, Y\right)-\frac{1}{2} \cdot \frac{\rho}{W_{0}+E(\tilde{\pi})} \cdot Y^{2} \cdot \sigma_{P_{Y}}{ }^{2}
$$

s.t. $E(\tilde{\pi})=\mu_{P_{Y}} . Y-C\left(P_{C I}, R, Y\right)+D P$

The optimal production quantity is thus implicitly determined by the first order condition ${ }^{3}$ :

$$
\left(\mu_{P_{Y}}-C_{Y}\left(P_{C I}, R, Y\right)\right),\left(1+\frac{1}{2} \cdot \frac{\rho \cdot Y^{2} \cdot \sigma_{P_{Y}}{ }^{2}}{\left(W_{0}+E(\tilde{\pi})\right)^{2}}\right)-\frac{\rho \cdot Y \cdot \sigma_{P_{Y}}{ }^{2}}{W_{0}+E(\tilde{\pi})}=0
$$

With

$$
C_{Y}\left(P_{C I}, R, Y\right)=\frac{\partial C\left(P_{C l}, R, Y\right)}{\partial Y}=\frac{C\left(P_{C I}, R, Y\right)}{\theta . Y}
$$

\section{Comparative statics}

Equations (7) and (9) define the behaviour of the farm household. We complete the system with the specification of the land supply function:

$$
T=\beta_{T} \cdot R^{\varepsilon_{T}}
$$

First differentiation of these equations allows us to identify the impact on production and land rental rates of direct payments and of an output subsidy (which is equivalent in this framework to an increase of the expected price):

$$
\begin{aligned}
& \frac{\partial Y}{\partial D P}=\frac{1}{D} \frac{\rho \cdot Y \cdot \sigma_{P_{Y}}{ }^{2}}{\left(W_{0}+E(\tilde{\pi})\right)^{2}}\left(1-\frac{Y \cdot\left(\mu_{P_{Y}}-C_{Y}(.)\right)}{W_{0}+E(\tilde{\pi})}\right) \\
& \frac{\partial Y}{\partial \mu_{P_{Y}}}=\frac{1}{D}\left(1+\frac{\rho \cdot Y^{2} \cdot \sigma_{P_{Y}}{ }^{2}}{2 \cdot\left(W_{0}+E(\tilde{\pi})\right)^{2}}+Y \cdot \frac{\rho \cdot Y \cdot \sigma_{P_{Y}}{ }^{2}}{\left(W_{0}+E(\tilde{\pi})\right)^{2}}\left(1-\frac{\left.Y \cdot\left(\mu_{P_{Y}}-C_{Y}(.)\right)\right)}{W_{0}+E(\tilde{\pi})}\right)\right) \\
& \frac{\partial R}{\partial Y}=\frac{R}{\theta \cdot Y} \frac{1}{\varepsilon^{T}+\sigma \cdot s^{I}}
\end{aligned}
$$

With 


$$
\begin{aligned}
D & =C_{Y Y}(.) \cdot\left(1+\frac{1}{2} \cdot \frac{\rho \cdot Y^{2} \cdot \sigma_{P_{Y}}{ }^{2}}{\left(W_{0}+E(\tilde{\pi})\right)^{2}}\right)+\frac{\rho \cdot \sigma_{P_{Y}}{ }^{2}}{W_{0}+E(\tilde{\pi})} \cdot\left(1-\frac{Y \cdot\left(\mu_{P_{Y}}-C_{Y}(.)\right)}{W_{0}+E(\tilde{\pi})}\right)^{2} \\
& +\left(C_{Y R}(.) \cdot\left(1+\frac{1}{2} \cdot \frac{\rho \cdot Y^{2} \cdot \sigma_{P_{Y}}{ }^{2}}{\left(W_{0}+E(\tilde{\pi})\right)^{2}}\right)+\frac{T \cdot Y \cdot \rho \cdot \sigma_{P_{Y}}{ }^{2}}{\left(W_{0}+E(\tilde{\pi})\right)^{2}} \cdot\left(1-\frac{Y \cdot\left(\mu_{P_{Y}}-C_{Y}(.)\right)}{W_{0}+E(\tilde{\pi})}\right)\right) \cdot\left(\frac{R}{\theta \cdot Y} \cdot \frac{1}{\varepsilon^{T}+\sigma_{\cdot} S^{I}}\right)
\end{aligned}
$$

And $s^{I}=\frac{P_{C I} I}{R \cdot T+P_{C I} I}$ is the share of the other variable inputs in total variable expenditures.

From the assumption of decreasing returns to scale, we have:

$1-\frac{Y \cdot\left(\mu_{P_{Y}}-C_{Y}(.)\right)}{W_{0}+E(\tilde{\pi})}>0$

And thus the denominator expression $\mathrm{D}$ is always positive. Consequently an increase in the direct payment increases the production (equation 12). As expected it appears that there is no effect when the relative risk aversion coefficient is null. On the contrary the impact of an output subsidy on production is always positive even if the relative risk aversion coefficient is null (equation 13). Finally both farm programs increase the land rental rates (equation 14). It is more interesting to compare the effects of these two instruments for a given public expenditure and starting from a no support situation $\left(\partial D P=Y . \partial \mu_{P_{Y}}\right)$. The relative impact on production is thus given by:

$$
\frac{\partial Y}{Y \partial \mu_{P_{Y}}}-\frac{\partial Y}{\partial D P}=\frac{1}{D}\left(\frac{1}{Y}+\frac{\rho \cdot Y \cdot \sigma_{P_{r}}{ }^{2}}{2 \cdot\left(W_{0}+E(\tilde{\pi})\right)^{2}}\right)
$$

We thus find the standard result that, for a given public expenditure, an output subsidy has a higher production impact than a direct payment. But this first framework also implies (equation 14) that this output subsidy has a higher impact on land rental rates than a direct payment. This is so because the latter is assumed to be kept by the farm producer for the remuneration of the fixed human capital. Landowners thus do not benefit from direct payments, a result which is in contradiction with many empirical studies (Bhaskar and Beghin 2007b).

\section{Explaining farm wealth and identifying the final beneficiary of direct payments}

\section{Farm household's wealth and land values: a cursory literature review}

In all studies on the decoupling of agricultural farm programs, the initial wealth of farm households is assumed to be fixed. According the United States Department of Agriculture (Mishra et al. 2002), this wealth is mainly constituted by the value of the agricultural land that they own. Moreover agricultural land is mainly owned by farm households. Then it is important to clearly understand the formation of land values. In that respect, many theoretical and empirical works have tried to explain the land (rental/selling) price. They all show that agricultural profits and farm programs positively influence this price. They also show that the agricultural land is a particular asset because the income expectation is lower than for other assets and the income variability is simultaneously higher (Erickson et al. 2004). This suggests that asset markets are segmented. Chavas and Thomas (1999) showed the importance of transaction costs on the buying/selling of agricultural land, the nature of inter-temporal preferences of investors and their attitude toward risk allow explaining this particularity. In 
other words the agricultural land asset is not directly substitutable to other assets and farm households are the more affected by a modification of the value of this asset. Regarding the distribution of direct payments between farmers and land owners, both US and EU farm producers get these direct payments only under some conditions. In particular they must have some eligible land (base acreage in the US, reference acreage in the EU). These direct payments are in fact defined as the product of a fixed amount per acre/hectare unit $(d p)$ and a historical acreage $\left(T_{H}\right)$. Accordingly these producers must farm this acreage to get the direct payments. If the producer is purely a renter, then he may not perceive at all the direct payments due to increased rental rates. That depends on the farm land regulations. In the US case that we will refer to in the simulation section, renters cannot acquire base and thus always pay the full costs of program benefits to the land owner (Duffy et al. 1994).

In sum, the wealth of a farm household is mainly composed of the land asset and farm programs have a significant impact on the land values. So it seems appropriate to introduce these two characteristics in the conceptual framework.

\section{Our conceptual framework}

In order to include these two characteristics, it is useful to distinguish the farm producer, the farm household and the landowner. Suppose first the extreme case of a producer renting all his land and whose wealth is in terms of non agricultural asset (denoted $W N F$ ). His landowner knows that he needs the land to get the direct payments and can thus increase the rent in order to collect the benefits of subsidies (Duffy et al. 1994). This is in fact one of the most important criticisms against the direct payments system (Goodwin et al. 2005 for instance). The wealth effect of direct payments is null for such a producer because his program is given by:

$$
\begin{aligned}
\max _{Y, I, T} E C & =W N F+\mu_{P_{Y}} \cdot Y-P_{C I} \cdot I-R \cdot\left(T-T_{H}\right)-(R+d p) \cdot T_{H}+d p \cdot T_{H}-\frac{1}{2} \cdot \frac{\rho \cdot Y^{2} \cdot \sigma_{P_{Y}}{ }^{2}}{W N F+E(\tilde{\pi})} \\
& =W N F+\mu_{P_{Y}} \cdot Y-P_{C I} \cdot I-R \cdot T-\frac{1}{2} \cdot \frac{\rho \cdot Y^{2} \cdot \sigma_{P_{Y}}{ }^{2}}{W N F+\mu_{P_{Y}} \cdot Y-P_{C I} \cdot I-R \cdot T} \\
\text { s.t. } \quad Y & =\alpha_{0} \cdot\left(\alpha_{1} \cdot I \frac{\sigma-1 / \sigma}{\sigma}+\left(1-\alpha_{1}\right) \cdot T^{\sigma-1 / \sigma}\right)^{\sigma \cdot \theta / \sigma-1}
\end{aligned}
$$

In this program, the direct payment no longer appears and thus has no direct impacts on the production level of this farm. From this program, it must also be clear that there are two rental prices of land: the level $R$ on the acreages non eligible to direct payments and $R+d p$ on the others. Even this producer does not change his behaviour due to the introduction of direct payments, the average land rental price increases with this direct payment.

Let's turn now to the more realistic case of a farm household who partially owns his land. Land in property is furthermore supposed to be lower than historical land eligible to direct payments. His initial wealth is then determined by:

$W_{0}=W N F+\left(\frac{R}{\tau_{R}}+\frac{d p}{\tau_{d p}}\right) T_{P}$

Where $T_{P}$ is the quantity of land owned by the household, and $\tau_{R}, \tau_{d p}$ the actualisation rates applied respectively to the land rental price and the direct payment. The wealth of this farm 
household thus depends on the non agricultural assets (assumed fixed in this analysis) and the total value of land in property. Like Lamb and Henderson (2000) for instance, we assume that the land value depends on its rental price and on the unitary direct payment. The expression of wealth is obviously simplified because it does not explicitly include any risky components for non agricultural assets neither for land. They are however implicitly in the different actualisation rates of the three components of wealth. The maximisation program of this farm household is given by:

$$
\begin{aligned}
& \max _{Y, I, T} E C=W N F+E(\tilde{\pi})-\frac{1}{2} \cdot \frac{\rho \cdot Y^{2} \cdot \sigma_{P_{Y}}{ }^{2}}{W N F+\left(\frac{R}{\tau_{R}}+\frac{d p}{\tau_{d p}}\right) \cdot T_{P}+E(\tilde{\pi})} \\
& \begin{aligned}
E(\tilde{\pi}) & =\mu_{P_{Y}} \cdot Y-P_{C I} \cdot I-R \cdot\left(T-T_{H}\right)-(R+d p) \cdot\left(T_{H}-T_{P}\right)-(R+d p) \cdot T_{P}+d p \cdot T_{H} \\
& =\mu_{P_{Y}} \cdot Y-P_{C I} \cdot I-R \cdot T
\end{aligned} \\
& \text { s.t. } \quad Y=\alpha_{0} \cdot\left(\alpha_{1} \cdot I \frac{\sigma-1 / \sigma}{\sigma}+\left(1-\alpha_{1}\right) \cdot T^{\sigma-1 / \sigma}\right)^{\sigma \cdot \theta / \sigma-1}
\end{aligned}
$$

The direct payment enters the maximisation program only through the explanation of the initial wealth. On the contrary it does no longer appear in the current expected profit because we assume a perfect land market. Accordingly this farm household has the possibility to rent out his land eligible to direct payment.

First order conditions of the new program for an interior solution are very similar to the standard ones (equations 7 and 9). The implicit equation defining the optimal supply has the same structure. Just the expression of final wealth is modified:

$$
\begin{aligned}
& \left(\mu_{P_{Y}}-C_{Y}\left(P_{C I}, R, Y\right)\right)\left(1+\frac{1}{2} \cdot \frac{\rho \cdot Y^{2} \cdot \sigma_{P_{Y}}{ }^{2}}{W F^{2}}\right)-\frac{\rho \cdot Y \cdot \sigma_{P_{Y}}{ }^{2}}{W F^{2}}=0 \\
& \text { with } W F=W N F+\left(\frac{R}{\tau_{R}}+\frac{d p}{\tau_{d p}}\right) T_{P}+\mu_{P_{Y}} . Y-C\left(P_{C I}, R, Y\right)
\end{aligned}
$$

\section{The comparative statics}

In order to analyse the effects of an output subsidy and of a direct payment, we assume that the latter occurs through a change of the unitary direct payment (this will ease comparison for an equal budgetary cost). Total differentiation of equations (7), (11) and (19) leads to:

$$
\begin{aligned}
& \frac{\partial Y}{\partial d p}=\frac{1}{\widetilde{D}} \frac{\rho \cdot Y \cdot \sigma_{P_{Y}}{ }^{2}}{W F^{2}}\left(1-\frac{Y \cdot\left(\mu_{P_{Y}}-C_{Y}(.)\right)}{W F}\right) \cdot \frac{T_{P}}{\tau_{d p}} \\
& \frac{\partial Y}{\partial \mu_{P_{Y}}}=\frac{1}{\widetilde{D}}\left(1+\frac{\rho \cdot Y^{2} \cdot{\sigma_{P_{Y}}}^{2}}{2 \cdot W F^{2}}+Y \cdot \frac{\rho \cdot Y \cdot \sigma_{P_{Y}}{ }^{2}}{W F^{2}}\left(1-\frac{Y \cdot\left(\mu_{P_{Y}}-C_{Y}(.)\right)}{W F}\right)\right)
\end{aligned}
$$

With 


$$
\begin{aligned}
\widetilde{D} & =C_{Y Y}(.) \cdot\left(1+\frac{1}{2} \cdot \frac{\rho \cdot Y^{2} \cdot{\sigma_{P_{Y}}}^{2}}{W F^{2}}\right)+\frac{\rho \cdot \sigma_{P_{Y}}{ }^{2}}{W F} \cdot\left(1-\frac{Y \cdot\left(\mu_{P_{Y}}-C_{Y}(.)\right)}{W F}\right)^{2} \\
& +\left(C_{Y R}(.) \cdot\left(1+\frac{1}{2} \cdot \frac{\rho \cdot Y^{2} \cdot \sigma_{P_{Y}}{ }^{2}}{W F^{2}}\right)+\left(T-\frac{T_{p}}{\tau_{d p}}\right) \frac{Y \cdot \rho \cdot \sigma_{P_{Y}}{ }^{2}}{W F^{2}} \cdot\left(1-\frac{Y \cdot\left(\mu_{P_{Y}}-C_{Y}(.)\right)}{W F}\right)\right) \cdot\left(\frac{R}{\theta \cdot Y} \cdot \frac{1}{\varepsilon^{T}+\sigma \cdot s^{I}}\right)
\end{aligned}
$$

The impact on the rental price of land is still given by equation (14). The sign of the new denominator can not be determined without ambiguity. If negative, this implies that the optimal supply of our farm household increases with the land rental price. This possibility can not be ruled out in theory and the economic interpretation is as follows. On a one hand, an increase of the rental price of land increases the production cost of the farm producer and thus reduce the production incentive. On a second hand, an increase of the rental price of land increases the wealth of farm household, which in turn stimulates production of a risk averse agent. With standard values of behavioural parameters (elasticity of land supply, substitution elasticities and values of final wealth), this possibility does not appear empirically. Disregarding this case, the impacts of an output subsidy and a direct payment on production and land rental rates remain positive. The comparison with former impacts (equation 12,13) is not immediate because the denominators are not strictly the same. We can nevertheless remark that the production impact of direct payment may be greater than previously recognized, especially if the actualisation rate of direct payment is low. We can also remark that the two denominators are the same if the land supply elasticity is infinite. In this case, it is readily apparent that the direct payment has now a larger impact on the production by an amount equal to the inverse of the actualisation rate. On the other hand, the production impact of output subsidies remains the same.

For a same budgetary cost and starting from a situation without farm programs, the relative impact of these two farm programs on the production is given by:

$$
\frac{\partial Y}{Y \partial \mu_{P_{Y}}}-\frac{\partial Y}{T_{H} \partial d p}=\frac{1}{\widetilde{D}}\left(\frac{1}{Y}+\frac{\rho \cdot Y \cdot \sigma_{P_{Y}}{ }^{2}}{2 \cdot W F^{2}}+\frac{\rho \cdot Y \cdot \sigma_{P_{Y}}{ }^{2}}{2 \cdot W F^{2}}\left(1-\frac{Y \cdot\left(\mu_{P_{Y}}-C_{Y}(.)\right)}{W F}\right) \cdot\left(1-\frac{T_{P}}{T_{H} \cdot \tau_{d p}}\right)\right)
$$

Assuming that the denominator is always positive, this last expression shows that it is still impossible to determine the relative production impact of direct payments and output subsidies. Again, if the actualisation rate of direct payments is low, it can not be ruled out that direct payments have a greater production impact than equal cost output subsidies. By extension, their impact on the rental price of land non eligible to payment may be greater. Finally their impact on the average rental price of land may be much greater too.

In sum the explanation of the wealth of farm households can theoretically increase the coupling effects of different agricultural policy instruments. Even if it is not possible to compare these increased coupling effects in all cases, we show in a simple case that this is more likely for direct payments than for output subsidies. Simultaneously we clearly identify in our conceptual framework the ultimate beneficiary of direct payments. Contrary to current analyses, we thus acknowledge the capitalisation of farm support in land values. How these modifications impact the different results is an empirical matter, to which we turn now.

\section{Calibration of an empirical model}

The conceptual framework described herein is obviously very simplified compared to the reality of farm households who realize several productions (and not only one) using several 
inputs (and not only three) and facing several sources of risk (and not only the price risk). However our main objective in this article is to identify the influence of wealth actualisation in the estimation of the decoupling degree farm programs. So we can still apply this framework to a representative US farm producing corn only. The model parameters are first obtained from the USDA publication on the characteristics and production costs of corn specialized farms in 2001 (Foreman 2006, tables 1 and 3). We use the average production costs given in these tables. We thus assume the existence of a domestic farm of 670 acres. The representative farm household owns $60 \%$ of his initial area. 146 bushels per acre are produced and are valued 2 dollars per bushel $(6 \%$ of which come from the loan deficiency payment program). The operational costs are 172 dollars per acre and the opportunity cost of land is 86 dollars per acre. The household's profit (remunerating his human capital and the risk premium) is thus 34 dollars per acre excluding direct payments. According to the OECD (ESP database), direct payments for corn in 2001 amount to 3802 million dollars and 75 million acres were allocated to corn. Accordingly the direct payments represent 50 dollars per cultivated acre. The base area is however at the most equal to $85 \%$ of the cultivated area and we thus assume that this direct support is paid on only $85 \%$ of the area. The support is then equal to 58.8 dollars per eligible acre.

Concerning the initial wealth of the household, the initial net value of the farm is equal to 383 thousands dollars. At the macroeconomic level the land value represents $80 \%$ of the agricultural assets. This farm owns $60 \%$ of its land, so the agricultural land is valued 1560 dollars per acre. This value is lower than the agricultural land value of the states in the Corn Belt (the value reaches 2000 dollars per acre in Iowa and Illinois for instance) but largely higher than the agricultural land value at the national level (1100 dollars per acre). We thus adopt this value in the calibration of the model.

We also have to calibrate the non agricultural assets owned by the household. According to Mishra et al. (2002), 69\% of the net wealth of farm households is made of agricultural assets. Yet this proportion reaches $90 \%$ for the farms making positive profits (that are the farms realising most of the agricultural productions). As the farm we model initially makes profit, we assume that only $10 \%$ of the initial net wealth includes non agricultural assets. The value of non agricultural assets is then 87 thousands dollars and the total net wealth 870 thousands dollars.

To determine the value of elasticities we use the summary of Abler (2001). The substitution elasticity between land and variable inputs is thus fixed at 0.4, the land supply elasticity at 0.1 and finally the other input aggregate (capital and intermediate consumptions) supply elasticity at 1 (we introduce a supply function similar to the land one, as this is done in Mullen et al. 2001). We use the econometric estimations of Mullen et al. (2001) and Moledina et al. (2004) to calibrate the coefficient of variation of corn price at 0.2 (that is a variance of 0.16 ). Like authors (Lamb and Anderson 2000) we assume the same actualisation rate in the initial wealth formula (7.4\%). The underlying assumption is that the uncertainty concerning the durability of direct payments is discounted in the same manner by the farm household as the uncertainty of the market returns.

It just remains one parameter to completely calibrate the model. We can either fix the initial level of relative risk aversion or fix the level of returns to scale. Indeed these to parameters are linked in equation (9) which implicitly defines the production level. Here we fix the relative risk aversion coefficient at 5 , this implies returns to scale of 0.92 . In other words $8 \%$ of the production value is used to pay the fix factor and the risk premium is initially 4132 dollars that is $2.1 \%$ of the production value. 


\section{Illustrative simulations}

In this fourth section we present simulations in order to illustrate the importance of our modifications. We thus simulate the impact of removing direct payments according to the two conceptual frameworks. We also simulate the removal of a hypothetical output subsidy leading to the same static effect on farm revenue. Practically we reduce the expected price by 17\%. Results are reported in Table 1.

In the first row we report the effects of a $1 \%$ expected price decrease, so as to compute the price elasticity and further legitimate our calibration choices. It is well known that in a deterministic framework the price elasticity of the product depends on the price elasticities of the factors supply and on the substitution between factors in the production technology (see for instance, Hertel 1989). The producer's profit is then used to pay the fixed factor invested in the activity by the household if this factor is unique. In addition, when the risk aversion is introduced, this elasticity depends on the repartition of profit between the risk premium of the household (which is sensitive to price) and this (residual) income of fixed factor. Consequently the price elasticity of production is more important when the risk aversion is taken into account. The estimated elasticities are 0.4 without risk aversion and 0.44 with risk aversion. These values are consistent with the elasticities estimated by the USDA (Lin et al. 2000), which confirm our choices for the different parameters.

With the standard modelling of risk averse farmers, (second row of table 1), the suppression of direct payments leads to a very limited decrease in production $(0.067 \%)$. The main effects are a reduction of the farm household's profit (59\%) and a slight decrease in his final wealth $(3.58 \%)$. The wealth elasticity of production is thus very low $(0.029)$ which is common in econometric estimations (Serra et al. 2006). Still under the same assumption, the removal of the hypothetical output subsidy (leading to the same static effect on the farm total revenue) leads to an $8 \%$ decrease in production (ex post elasticity of 0.47 ). The production impact is thus much larger by a factor of 119 . This ratio is not unrealistic; OECD (2004) for instance estimated the effect of on a marginal output subsidy of one dollar 66 times higher than the effect of a marginal direct payment of one dollar. Our estimation is thus higher in spite of a higher relative risk aversion coefficient ( 5 instead of 2 ). The difference in production ratio can be explained by the fact that the OECD's analysis assumes that the household's wealth include the off-farm revenues only. In other words the initial wealth is relatively low compared to the farm household's profit. We can reproduce this ratio (66) with relative risk aversion coefficient of 2 by assuming that the initial wealth of our representative farmer is $57 \%$ lower. This result reinforces our main idea to correctly measure the initial wealth of farm households. This idea is reinforced again by the analysis of the consequences of these two instruments on the rental price of land. The production subsidy instrument has a noted effect on this price ( $28 \%$ decrease) whereas the direct payment effect is nearly null $(0.27 \%)$. This contradicts the great majority of economic studies which conclude that this support is strongly capitalized in land.

When we use our conceptual framework (third row of table 1) then the production effect of direct payments is not negligible anymore $(1.2 \%)$. This can be explained by the fact that the (initial or final) wealth of the farm household is now seriously decreased -more than $37 \%$ ). The wealth elasticity of production is still low (0.03) and consistent with econometric estimates. The effect of a reduction of the price expectation is reinforces too but less than previously ( $8.4 \%$ instead of $8 \%$ ) because here again the initial (and final) wealth decreases more. The strongest result concerns the production effects ratio: it is now 7.5 instead of 119 previously. 


\section{Simulations of the effects of the US corn policy}

The previous simulations allow appreciating the need to actualise the initial wealth to measure the effects of direct payments. We now measure the effects of the US corn policy applied in 2001, first using the standard framework where the initial wealth is fixed and the final beneficiary of the support is not clearly identified, second when the initial wealth is actualised and direct payments are capitalized in land values. This simulation assumes the suppression of direct payments, a $6 \%$ decrease in the product price expectation. This is the initial amount of output subsidy reported in the OECD PSE database (the underlying assumption is that the producer is a small producer on the world market). We also assume a $70 \%$ increase of the variance of the price received by the producer following the suppression of the loan deficiency payment (from Mullen et al. 2001). These three shocks (direct payments, expectation and variance of price) are applied individually and then simultaneously to appreciate the cumulative effect of the different instruments. This simulation of the effects of the US corn policy is obviously only illustrative because we do not take into account the effects of the policies applied to the other sectors. Again this does not prevent us from identifying the importance of a correct measurement of wealth in this simplified simulation.

The results are presented in table 2 . With the traditional modelling the suppression of the US corn policy leads to a $4.1 \%$ decrease of production. This decrease is essentially $(66 \%)$ due to the reduction of price expectation and to a lesser extent (31\%) to the increase in price variance (same proportions as in OECD, 2004). Unsurprisingly the effect of direct payments which only passes through the wealth effect is very low $(2 \%)$. The total effect almost corresponds to the effect of each instrument.

When we actualise wealth and recognize the capitalisation of the direct payments in land values, then the suppression of the US corn policy leads to a $6.84 \%$ decrease in production which is a $68 \%$ more important effect. Furthermore the effect of the price support (via the decrease in expectation and the increase in variance) is relatively marginally modified $(4.3 \%$ instead of $4 \%$ ). On the contrary the effect of the direct payment is now clearly more important $(1.1 \%)$ and finally the effects of instruments are not simply cumulative anymore. The total effect is not equal to the sum of effects. This comes from the non linearity induced by the wealth effect.

\section{Conclusion}

The recent agricultural policies reforms in developed countries introduced direct payments to the detriment of traditional instruments enhancing production. Several channels through which these new instruments can impact production have been identified. Particularly these direct payments increase farm households' wealth, which reduce the risk premium of the risk averse households. However available studies estimate that this effect is empirically low. In this article, we have revisited this measurement of the coupling effect through wealth for risk averse farm houscholds. Indeed their initial wealth is always assumed to be fixed whereas it is essentially determined by the agricultural land value. So we have theoretically and empirically demonstrated that the actualisation of the initial wealth to the evolution of the agricultural policy considerably modify the measurement of the coupling effect of direct supports and more marginally of traditional instruments. A simulation of the suppression of the US corn policy illustrates the importance of this actualisation. The coupling effect of the US policy on corn production is underestimated by $68 \%$ when the wealth is not actualised.

From a political point of view these results imply that the support instruments classified in the green box can really impact the production. The integration of this work in some more global 
analysis of agricultural policies is obviously a useful continuation to be considered. It would as well be useful to understand why simultaneously the agricultural land is mainly owned by farm households and their wealth is mainly in the agricultural land asset. Is it simply the consequence of the farmers' particular preferences? Or, on the contrary, does it result from some land regulation or tax policies which are in favour of farmers? If this is the case, our results suggest that it is important to consider simultaneously the direct and indirect agricultural income support policies.

\footnotetext{
${ }^{1}$ Econometric analysis chronologically include Sckokai and Anton 2005, Sckokai and Moro 2006, Serra et al. 2006, Goodwin and Mishra 2006, Lin and Dismukes 2007, McIntosh, Shogren, and Dohlman. 2007 Serra, Zilberman, and Gil 2007. Simulation modelling analysis include Young et Westcott 2000, Burfisher, Robinson, and Thierfelder 2000, Mullen et al. 2001, Anton et Le Mouel 2002, OECD 2004, Anton et Le Mouël 2004, Anton and Giner 2005, Just 2006.

${ }^{2}$ Goodwin and Mishra (2006) acknowledge in a footnote that this effect on wealth may be pertinent but their subsequent analysis do not capture it.

${ }^{3}$ Second order conditions of the maximisation program are automatically satisfied.
} 


\section{References}

Abler, D.G. 2001. "Elasticities of Substitution and Factor Supply in Canadian, Mexican and U.S. Agriculture." In OECD, ed. Market Effects of Crop Support Measures, Annex 2. Paris:OECD.

Anton, J., and C. Le Mouel. 2002. "Risk effects of crop support measures." Available at www.gtap.org.

Anton, J., and C. Le Mouel. 2004. "Do counter-cyclical payments in the 2002 US Farm Act create incentive to produce?" Agricultural Economics 31(2-3):277-284.

Anton, J., and C. Giner. 2005. "Can Risk Reducing Policies Reduce Farmer's Risk and Improve Their Welfare?" Paper presented at the $11^{\text {th }}$ Congress of the European Association of Agricultural Economists, Copenhaguen, Denmark, August, 24-27.

Benjamin, D. 1992. "Household composition, labor markets, and labor demand : testing for separation in agricultural household models." Econometrica 60(2):287-322.

Bhaskar, A., and J. Beghin. 2007a. "Decoupled farm payments and the role of base updating under uncertainty." Working paper 07026, Iowa State University, Department of Economics.

Bhaskar, A., and J. Beghin. 2007b. "How coupled are decoupled farm payments? A review of coupling mechanisms and the evidence." Working paper 07021, Iowa State University, Department of Economics.

Burfisher, M., S. Robinson, and K. Thierfelder. 2000. "North American farm programs and the WTO." American Journal of Agricultural Economics 82(3): 768-774.

Chambers, R.G.. 1995. "The incidence of agricultural policies.” Journal of Public Economics 57(2): 317-335.

Chau, N.H,. and H. de Gorter. 2005. "Disentangling the Consequences of Direct Payment Schemes in Agriculture on Fixed Costs, Exit Decisions, and Output." American Journal of Agricultural Economics 87(5):1174-1181.

Chavas J.P., and A. Thomas. 1999. "A dynamic analysis of land prices.” American Journal of Agricultural Economics 81(4):772-784.

Courleux, F., H. Guyomard, F. Levert, and L. Piet. 2007. "How the EU Single Farm Payment should be modelled: lump-sum transfers, area payments or... something else?" Paper presented at the INRA -SFER conference, Paris, France, December, 13-14.

Duffy, P.A., C.R Taylor, D.L. Cain, and G.J. Young. 1994. "The Economic Value of Farm Program Base." Land Economics 70(3):318-29.

Erickson, K.W., C.B. Moss, and A.K. Mishra. 2004. "Rates of return in the farm and nonfarm sectors: how de they compare?" Journal of Agricultural and Applied Economics 36(3):789795.

Foreman, L. 2006. "Characteristics and production costs of U.S. corn farms, 2001." EIB-7, U.S. Dept of Agriculture, Economic Research Service, Economic Information Bulletin Number 7, February 2006.

Goodwin, B.K., A.K. Mishra, and F. Ortalo-Magné. 2005. "Landowner's riches: the distribution of agricultural subsidies." Working paper.

Goodwin, B.K., and A.K. Mishra. 2006. "Are "decoupled" farm program payments really decoupled? An empirical evaluation." American Journal of Agricultural Economics 88(1):7389. 
Hennessy, D.A. 1998. "The production effects of agricultural income support policies under uncertainty." American Journal of Agricultural Economics 80(1):46-57.

Hertel, T.W. 1989. "Negotiating reductions in agricultural support: implications of technology and factor mobility." American Journal of Agricultural Economics 71(3):559-573.

Just, R.D. 2006. "Calibrating the wealth effects of decoupled payments: does decreasing absolute risk aversion matter?" Paper presented at the Annual Meetings of SCC-76 Economics and Management of Risk in Agriculture and Natural Resources, Myrtle Beach, SC, March 16-18.

Lamb, R.L., and J. Henderson. 2000. "FAIR Act implications for land values in the corn belt." Review of Agricultural Economics 22(1):102-119.

Lin, W., and R. Dismukes. 2007. "Supply response under risk: implications for countercyclical payments' production impact." Review of Agricultural Economics 29(1):64-86.

Lin W., P. Westcott, R. Skinner, S. Sanford, and D. De La Torre Ugarte. 2000. "Supply Response Under the 1996 Farm Act and Implications for the U.S. Field Crops Sector." USDA-ERS Technical Paper 1888

McIntosh, C.R., J.F. Shogren, and E. Dohlman. 2007. "Supply response to countercyclical payments and base acre updating under uncertainty: an experimental study." American Journal of Agricultural Economics 89(4):1046-1057.

Mishra, A.K., H.S. El-Osta, M.J. Morehart, J.D. Johnson, and J.W. Hopkins. 2002. "Income, wealth, and the economic well-being of farm households." Farm Sector Performance and Well-Being Branch, Resource Economics Division, Economic Research Service, U.S. Department of Agriculture. Agricultural Economic Report No. 812.

Moledina, A.A., T.L. Roe, and M. Shane. 2004. "Measuring commodity price volatility and the welfare consequences of eliminating volatility." Paper Presented at the American Agricultural Economics Association Annual Meeting, Denver, CO, August 1-4.

Mullen, K., N. Chau, H. de Gorter, and B. Gloy. 2001. "The risk reduction effects of direct payments on U.S. wheat production." Working Paper.

OECD. 2001a. "Market Effects of Crop Support Measures." OECD, Paris.

OECD. 2004. "Risk effects of PSE crop measures." OECD, Paris.

Phimister, E. 1995. "Farm household production in the presence of restrictions on debt: theory and policy implications." Journal of Agricultural Economics 46(3):371-380.

Sckokai, P., and J. Anton. 2005. "The degree of decoupling of area payments for arable crops in the European Union." American Journal of Agricultural Economics 87(5):1220-1228.

Sckokai, P., and D. Moro. 2006. "Modeling the reforms of the common agricultural policy for arable crops under uncertainty." American Journal of Agricultural Economics 88(1):43-56.

Serra, T., D. Zilberman, B. Goodwin, and A. Featherstone. 2006. "Effects of decoupling on the mean and variability of output." European Review of Agricultural Economics 33(3):269288.

Serra, T., D. Zilberman, and J.M. Gil. 2007. "Farm's technical inefficiencies in the presence of governments programs." Paper presented at the American Agricultural Economics Association Annual Meeting, Portland, OR, July 29-August 1.

Young, C., and P. Wescott. 2000. "How decoupled is U.S. agricultural support for major crops?" American Journal of Agricultural Economics 82(3):762-767. 
Table 1. Impacts of the suppression of direct payments and of output subsidies according to the conceptual frameworks (in \% related to the initial situation)

\begin{tabular}{|c|c|c|c|c|c|c|c|}
\hline & Production & Land use & $\begin{array}{l}\text { Land rental } \\
\text { price }\end{array}$ & Other inputs & Profit & Initial wealth & Final wealth \\
\hline $\begin{array}{l}\text { Price elasticities } \\
\text { No risk aversion, price }=-1 \% \\
\text { Risk aversion, price }=-1 \%\end{array}$ & $\begin{array}{l}-0,40 \\
-0,44 \\
\end{array}$ & $\begin{array}{l}-0,17 \\
-0,17 \\
\end{array}$ & $\begin{array}{l}-1,65 \\
-1,73 \\
\end{array}$ & $\begin{array}{l}-0,59 \\
-0,62\end{array}$ & & & \\
\hline \multicolumn{8}{|c|}{ Standard modelling with fixed initial wealth and lump sum direct payments } \\
\hline Initial Value & 97820 bushels & 670 acres & $86 \$ /$ acre & $\begin{array}{l}115240 \\
\text { (index) }\end{array}$ & $56280 \$$ & $870000 \$$ & $926280 \$$ \\
\hline $\begin{array}{l}\text { Suppression of direct payment } \\
\text { Suppression of output subsidy } \\
\text { Production ratio }\end{array}$ & $\begin{array}{l}-0,067 \\
-7,98 \\
119 \\
\end{array}$ & $\begin{array}{l}-0,027 \\
-3,23\end{array}$ & $\begin{array}{l}-0,27 \\
-27,95\end{array}$ & $\begin{array}{l}-0,096 \\
-11,05\end{array}$ & $\begin{array}{l}-59,06 \\
-8,38\end{array}$ & $\begin{array}{l}0 \\
0\end{array}$ & $\begin{array}{l}-3,58 \\
-0,51\end{array}$ \\
\hline \multicolumn{8}{|c|}{ Proposed modelling with actualised initial wealth and capitalisation of direct payments in land values } \\
\hline Initial value & 97820 bushels & 670 acres & $86 \$$ acre & $\begin{array}{l}115240 \\
\text { (index) }\end{array}$ & $22780 \$$ & $870000 \$$ & $892780 \$$ \\
\hline $\begin{array}{l}\text { Suppression of direct payment } \\
\text { Suppression of output subsidy } \\
\text { Production ratio }\end{array}$ & $\begin{array}{l}-1,11 \\
-8,37 \\
7.5\end{array}$ & $\begin{array}{l}-0,44 \\
-3,38\end{array}$ & $\begin{array}{l}-4,35 \\
-29,09\end{array}$ & $\begin{array}{l}-1,58 \\
-11,55\end{array}$ & $\begin{array}{l}18,36 \\
-15,88\end{array}$ & $\begin{array}{l}-38,88 \\
-15,55\end{array}$ & $\begin{array}{l}-37,42 \\
-15,55\end{array}$ \\
\hline
\end{tabular}


Table 2. Impacts of the suppression of the US corn policy in 2001 according to the conceptual frameworks (in \% related to the initial situation)

\begin{tabular}{|c|c|c|c|c|c|c|c|}
\hline & Production & Land & $\begin{array}{l}\text { Land rental } \\
\text { prices }\end{array}$ & Other inputs & Profit & Initial wealth & Final wealth \\
\hline \multicolumn{8}{|c|}{ Standard modelling with fixed initial wealth and lump sum direct payments } \\
\hline Initial value & 97820 bushel & 670 acres & $86 \$ /$ acre & $\begin{array}{l}115240 \\
\text { (index) }\end{array}$ & $56280 \$$ & $870000 \$$ & $926280 \$$ \\
\hline $\begin{array}{l}6 \% \text { decrease of price expectation } \\
70 \% \text { increase of price variance } \\
\text { Suppression of direct payment } \\
\text { Total }\end{array}$ & $\begin{array}{l}-2,67 \\
-1,25 \\
-0,067 \\
-4,07\end{array}$ & $\begin{array}{l}-1,07 \\
-0,50 \\
-0,027 \\
-1,00\end{array}$ & $\begin{array}{l}-10,21 \\
-0,50 \\
-0,27 \\
-15,2 \\
\end{array}$ & $\begin{array}{l}-3,77 \\
-1,77 \\
-0,096 \\
-5,73\end{array}$ & $\begin{array}{l}-2,98 \\
8,36 \\
-59,06 \\
-53,90 \\
\end{array}$ & $\begin{array}{l}0 \\
0 \\
0 \\
0\end{array}$ & $\begin{array}{l}-0,18 \\
0,51 \\
-3,58 \\
-3,27 \\
\end{array}$ \\
\hline \multicolumn{8}{|c|}{ Proposed modelling with actualised initial wealth and capitalisation of direct payments in land values } \\
\hline Initial value & $\begin{array}{l}97820 \\
\text { bushel }\end{array}$ & 670 acres & $86 \$ /$ acre & $\begin{array}{l}115240 \\
\text { (index) }\end{array}$ & $22780 \$$ & $870000 \$$ & $892780 \$$ \\
\hline $\begin{array}{l}6 \% \text { decrease of price expectation (i) } \\
70 \% \text { increase of price variance (ii) } \\
\text { Suppression of direct payment } \\
\text { Total } \\
\text { Total (i) }+ \text { (ii) }\end{array}$ & $\begin{array}{l}-2,79 \\
-1,39 \\
-1,11 \\
-6,84 \\
-4,31 \\
\end{array}$ & $\begin{array}{l}-1,12 \\
-0,56 \\
-0,44 \\
-2,76 \\
-1,73 \\
\end{array}$ & $\begin{array}{l}-10,64 \\
-5,41 \\
-4,35 \\
-24,37 \\
-16,00 \\
\end{array}$ & $\begin{array}{l}-3,94 \\
-1,97 \\
-1,58 \\
-9,50 \\
-6,04 \\
\end{array}$ & $\begin{array}{l}-5,59 \\
22,80 \\
18,36 \\
51,68 \\
17,08 \\
\end{array}$ & $\begin{array}{l}-5,69 \\
-2,89 \\
-38,88 \\
-49,58 \\
-8,55 \\
\end{array}$ & $\begin{array}{l}-5,69 \\
-2,24 \\
-37,42 \\
-47,00 \\
-7,90 \\
\end{array}$ \\
\hline
\end{tabular}

